\title{
How Crises Model the Modern World
}

\author{
Patrick Lagadec ${ }^{\mathrm{i}}$ \\ Senior Research Scientist at the Ecole Polytechnique \\ Palaiseau, France \\ Benjamin Topperi \\ Theoretical physicist (UPMC/ENS Ulm, France), junior science and technology advisor \\ Paris, France \\ Received 4 August 2011 \\ Accepted 12 March 2012
}

\begin{abstract}
Crises are our new reality. "Black swans" are increasingly becoming the norm; our systems, environments, contexts are structurally prone to crises. Doing more of the same will not be the appropriate way to deal with modern crises: a paradigm shift is needed, based on a more accurate understanding of the dynamics of complex systems. This paper is an invitation to change the theoretical vision of crisis and crisis management, and the education and training of all actors involved.
\end{abstract}

Keywords: Crises, Complex systems, Black swan, Fractal, Rapid reflection force

\section{Global crises and the rise of a new world}

Natural disasters. Mega-storms like Katrina, "assembly lines" of hurricanes striking vital assets and networks of our nations and continents; earthquakes threatening major dams' stability; tsunamis triggering large scale technological disasters and threatening millions, as the world population shifts towards the seashores; forest fires leading to cross-continental power failures... The very concept of "natural" disaster has to be revised in a time when nature can trigger technological disasters and technology can spark off natural upheavals. Simple categorizations are not valid anymore.

Industrial disasters. On March 11, a magnitude 9.0 earthquake, one of the most powerful earthquakes the world has ever known since modern recordkeeping began in 1900, combined with a destructive tsunami (with waves over 20 meters), hit Japan and triggered a series of nuclear disasters (level 7 on the INES scale). A devastated region, a vast area under nuclear radiation threat, the third greatest economic power in the world was left with shortages in energy and food supplies, and triggered unknown ripple effects for the months to come on a worldwide scale. The Japanese proved to be very well prepared for the well-known threat - an earthquake - but unprepared for such an outside-the-box challenge. In the nuclear area in particular, as confessed by the International Atomic Energy Agency chief: “The current international emergency response framework needs to be reassessed. It was designed largely in the wake of the Chernobyl disaster in 1986, before the information revolution. It reflects the realities of the 1980s, not of the 21st century" (Ref. 1). The global "fall out" appears to be borderless: the very perception of nuclear energy, our faith in technological advancement, and public trust in official governance, are at stake.

Financial crises. The Lehman Brothers collapse in September 2008 came as a shock, but on its heels came something more: systemic financial-economic upheaval, with the banking system calling for desperate rescue operations. And now, we are facing the intricacies of financial, economic, and social turbulences behind the incredible and unreadable perspectives of State failures. Greece, Italy, Portugal, Spain, ... The challenge is defying the best visions, techniques, usual habits - even the best experts on the 1929 crisis, which is not the ideal reference.

Social unrest. The stage was set for decades to come: nothing new would emerge in the Arab countries, under strict control. Yet what seemed 
P. Lagadec and B. Topper

impossible the previous day did happen, and the map became globally unpredictable. It all started with just one man, Al Bouazizi, a poor unemployed 26-year old Tunisian, who set himself on fire in front of a government building on December 17 of last year. A month later, Ben Ali fled to Saudi Arabia. "The March of Folly” (Ref. 2) could spread across the board. But many different maps had to be drawn: Egypt was not Tunisia; Libya was not Egypt; Syria was not Libya. The crucial challenge is not the lack of answers, but the difficulty of asking and framing the proper questions. The problem is no longer the "event with ripple effects" but the multifaceted challenging situation mixing hyper-local and hyper-global dynamics.

Emergency response and recovery. The conventional vision was to rush in and help countries in difficult situations after some disaster occurred. This vision and situation is increasingly shattered. Crises appear to be blossoming everywhere: at any one time, the world has to face about forty crises of different natures, with, for some, a risk of regional spillover able to destabilize international security. Crises change their scale due to demographic trends, and new types of humanitarian intervention could affect billions by 2030. Post-event intervention has now to deal within a proliferation of "failing States", with the development of extremely violent situations and the development of mafias at the local, national and international levels (Ref. 3).

Whatever the frontline, the same kind of difficulty comes to the fore: conventional visions of crises and crisis management are thrown into an uncharted wilderness. We are confronted with a global volatile world, with novel textures and foundations - where the tiniest change can result in a global and unmapped dynamic.

The challenge is to prepare the conditions to deal with this new landscape. Our conventional vision of risks and crises has to evolve accordingly. This contribution modestly aims at proposing some preliminary inputs to facilitate such a huge program. A new vision and practice of crisis management is required.

\section{Why do we continually appear to be a disaster behind?}

The most recent crises are illustrations of a global dynamic. The words written by the House of Representatives after Hurricane Katrina, come to mind: "Why do we continually appear to be a disaster behind?” (Ref. 4).

\subsection{Crisis management in crisis}

Hegel's remark in Lectures on the philosophy of world history that "history is not the soil in which happiness grows" teaches us that crises are a constant of human societies. The names and dates of great crises are remembered and used to recall entire epochs, and they have influenced changes of societies, cultures and civilizations. However, in the past decades, crises have been multiplying exponentially, and man's power over them is looking increasingly fragile.

Urlich Beck has warned that modern man is presently living in a "risk society," obsessively preoccupied with his security and very sensitive to the slightest sign of its imperilment. Modern crises management practice (Refs 5-8) and theory (Refs. 9-10), even though it has been more and more precise in the characterization of complex systems with an ever larger set of parameters to act upon, has never taken the decisive step needed to deal with the world as it really is (Refs. 11-13).

There exists an extensive literature on the topic of crisis resulting in many definitions that overlap and sometimes diverge. Many have underlined and criticized such a hazy notion. However, they often miss the point. By essence, crisis is a very complex and elusive phenomenon. The very notion of crisis is structurally resistant to clear-cut definition and capture. Hence, crisis management theory cannot be so easily ensnared in usual frameworks. And crisis management cannot be a series of fixed, easy to teach and apply "best practices".

These last decades, crisis management has involved scholars from various disciplines (sociology, public administration, political science, international relations, organizational psychology, epidemiologists ...). Each discipline has tried to produce definitions, frameworks, and sometimes practical tools. This sophistication has not been a synonym for efficiency - especially when used to understand and deal with recent crises since the turn of the century. Any actions performed within the current crisis management paradigm forged in the 
1980s have had limited efficiency, and sometimes counter-productive consequences (Refs. 14-15).

Undoubtedly, the last few decades have witnessed an extraordinary development in the sciences and techniques of risk control and crisis management. But, cases are piling up to show that something is wrong with the current approach (Table 1).
How Crises Model the Modern World

question is increasingly eluding our crisis management rationale and governance.

Observing an event once does not imply that it will occur again in the future. In other words, there is no way to know that somewhere out there a black swan is not hiding, disproving the rule and nullifying our "knowledge" of swans. It points out the problem of

Table 1. Recalling some recent events.

\begin{tabular}{|c|c|c|c|}
\hline $\begin{array}{c}\text { Storm of } 1999 \text { over } \\
\text { Europe. }\end{array}$ & $9 / 11$ & Katrina, 2005 & Lehman Brothers, 2009 \\
\hline $\begin{array}{l}\text { "Nobody had } \\
\text { anticipated, after the first } \\
\text { alarming signals, the } \\
\text { runaway scenario that } \\
\text { happened." (Ref. 16) }\end{array}$ & $\begin{array}{l}\text { “On the morning of } 9 / 11 \text {, } \\
\text { the existing protocol was } \\
\text { unsuited in every respect } \\
\text { for what was about to } \\
\text { happen” 9/11 } \\
\text { Commission (Ref. 17). }\end{array}$ & $\begin{array}{l}\text { "It was not a hurricane, but } \\
\text { nobody understood that. It } \\
\text { was a weapon of mass } \\
\text { destruction without } \\
\text { criminal dimension." } \\
\text { Admiral Thad Allen } \\
\text { (Ref. 18) }\end{array}$ & $\begin{array}{l}\text { “No one knows what to do. } \\
\text { We are in a new territory } \\
\text { here. This is a new game. } \\
\text { They don't know what to } \\
\text { do.” Senator Majority Leader } \\
\text { Harry Reid (Ref. 19). }\end{array}$ \\
\hline
\end{tabular}

The core of the challenge appears to be in the bedrock of crisis theory and the very culture of crisis management. So far, the motto has been: let's define families of risks, let's plan in advance to prepare the best answers, to detect weak signals, and apply those best answers.

Today hyper-complex crises demand something else, and probably exactly at the opposite: the capacity to ask the tough questions, the preparation to navigate unmapped situations.

\subsection{When black swans become the norm}

Big departures from the mean, usual, or common state, or "black swans" (Ref. 20), used to be so rare that their effect could be considered negligible. All practices, regulations, policies, were set to address the regular occurrences only, as they were the one people were facing on a daily basis. Until now, we have been reasoning by induction, dealing only with "white swans", the common accidents. However, in a world where complexity and crises have become the new reality, such rare events have become so dramatic and so frequent that they cannot be excluded as simply marginal.

"Black swans" are increasingly becoming the norm, forcing us to search for new perspectives and a novel collective attitude towards risks and major crises. The intrinsic quality of the dynamics in inductive reasoning: we cannot really learn from our past experiences, and cannot always apply what has been learned in past crises to new crises.

This statement remains true regardless of the number of observations one adds to the pile. David Hume, quoted by N.N. Taleb, said that the observation of even a million white swans does not justify the statement "all swans are white." Planning is becoming much more difficult. Although it can help, it cannot be the driver.

The importance of knowledge, specifically knowledge of previous crises, is a question that can be raised, as new crises become more and more difficult to apprehend. Humans have a tendency to behave -almost without exception- as though they believe that experience teaches them lessons, in a very cause-consequence, past-present, "linear" line of thought.

This can be easily understood, as it has been very effective until recent times. One must understand the limits of induction, which shapes a world where past experience is a more fundamental knowledge than a deep, theoretical understanding of the framework we are working in. We still seem, at every turn, to lack this critical self-awareness, this realization that more of the same is not the solution.

This basic challenge becomes strategic when the 
P. Lagadec and B. Topper

issue is not only to be able to detect and deal with one black swan, but when black swans appear to be the "norm" in a very volatile world. Then, we are in a very difficult position, urging a more profound understanding of what is happening and more creativity.

\section{3. "Business as usual" and the collapse of the Roman Empire: why we need to act}

Our current situation is very similar to the apogee of the Roman Empire. The situation for someone living today is better than it has ever been in history. We have built connections between parts of the world that had never interacted before, creating a global interdependent economy. Like someone living at the apogee of the Roman Empire, very few clear signs indicate that it has reached the top of the hill. There is a refusal to see them, but the fall is near, unless we raise awareness about this fact on a global scale.

During the 3rd century A.D., the Roman Empire had to face a serious military crisis: invasions of foreign peoples and internal civil wars. The crisis was solved by Diocletian by doubling the size of the army, increasing taxes and enlarging bureaucracy; overall it was a considerable increase in complexity. The Roman Empire could not afford such a large army and, eventually, it destroyed itself in the attempt to maintain it.

Our society is reacting to the surge of crises much in the same way (Ref. 21). Despite all the talk of "saving" or "conserving" resources, or "regulating" some new practices, or "controlling” new technologies, it is clear that our society is not doing anything like that. We strive, certainly, towards more efficiency, regulation, control or security, but what is done in some areas or in some branch of the economy is not done in some other areas, in some other branches, due to ever more complex and interconnected societies. And that feedback loop is the loophole of complex societies. Complexity is all the economic, social, bureaucratic, and military structures that societies can create and manage, but only up to a certain point. Crises are piling up, and we are less and less able to face them.

We argue that, as the apogee of the Roman Empire, we are reaching that point of maximum disorder. And unless we do something about it, the world will slowly enter an era of Terra Incognita, facing successive global crises which could mean the decline of the industrial society as we know it. However, modern societies have developed a level of knowledge, a science of nature, which can be used to adapt to this growing volatility.

In the following part, we will make a careful detour through hard science to show how the appropriate paradigm shift can allow us to change the way we understand the emerging properties of dynamic interactions in a society and why current techniques are failing.

\section{Deep into science: a call for action}

In physics, dealing with complex systems usually starts with trying to linearize the equations involved i.e. getting rid of the complexity, exactly in the same way as black swans are diminished when events are modeled with a Gaussian curve.

This approach leads to quantitative results, which allow physicists to grasp an idea of the processes that are taking place near equilibrium. We argue that the way we are currently dealing with a crisis is similar to that over-simplified approach, but that recent major crises (Table 1) indicate that it has become ineffective (Ref. 22).

\subsection{A failing paradigm}

Crisis management is a comprehensive and cohesive set of processes which consist of four separate but related basic components: anticipation and preparation, rapid response, follow-through, and post-event evaluation.

In an ideal "white swan" world, seamless anticipation and preparation would eliminate all major crises. In reality, we are seeing time after time, event after event (Table 1), that "the best laid plans" become almost instantaneously irrelevant, if not counter-productive, in modern crises.

We will first start by trying to characterize the analogy we are making between linear systems and current crisis theory and discuss the reasons why it is failing.

Humanity started with small tribes, which grew stronger and larger; struggles over territory ensued. At the same time, agriculture was developed, which 
opened the possibility of trade and commercial ties. Social, cultural, and educational revolutions made their way, further strengthening the ties among individuals, but also increasing our dependence on one another.

The understanding that we could draw greater good from combining efforts and joining forces lead to the industrial era, and the information revolution. Yet they also have raised connections among humans up to a whole new and sophisticated level (Figure 1).

Thus, after tens of thousands of years, we are now realizing that, in the last decade or so, the world has become a global village, in which we are all connected socially, politically, and economically.

The attributes of the current paradigm of crisis management however still rely on the following assumptions:

(i) Events happen with a long characteristic time with respect to "regulation" time, i.e. once the risk has been identified, one has enough time to act before something irreversible happens ;

(ii) Well defined and spatially limited interactions between the various actors i.e. once the risk has been identified, one has enough control over the actors to act before something irreversible happens.

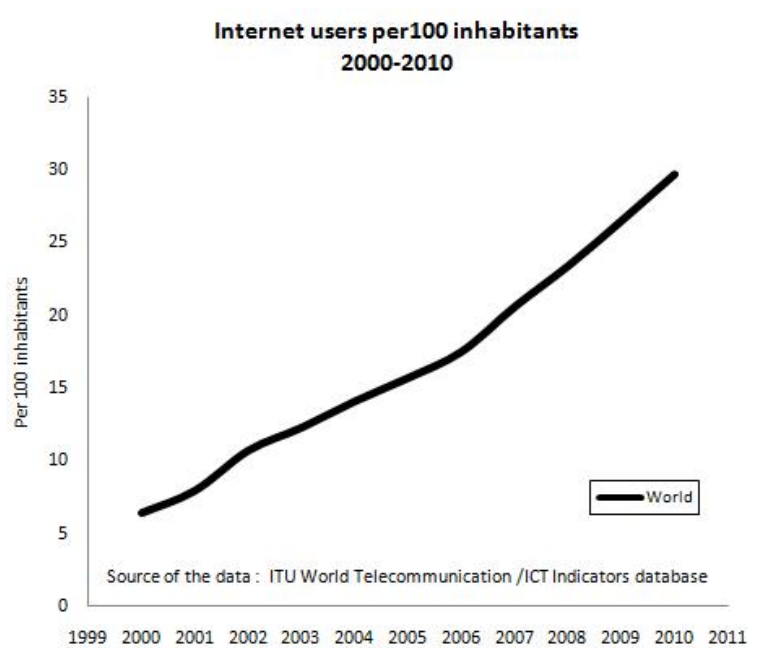

Figure 1. Evolution of the number of internet users in the world (2000-2010)
How Crises Model the Modern World

These two properties have, until the last decade or so, allowed effective control and limited crisis events.

However, it is clear that the validity domain for crisis management has become too small for the world as it is now (Figure 1).

In finance, decisions have to be taken fast, as the regulation time ( $\sim$ seconds) is much longer than the time of the actors ( milliseconds) (Ref. 23). With modern transportation, diseases can spread in a matter of hours: SARS, H1N1... Modern means of communication lead to an information deluge (which played a key role in the Arab world revolutions), and unverified rumors to spread, in matter of instants (twitter, etc.). Companies are global, they rely on just-in-time business, but controls and regulations are only effective on a national scale, and in specific sectors.

More important, interconnectivity and interdependence has become increasingly important and can lead to major disruption such as the North American power failures of 2003.

And at this very point in time, the fundamental change that began in the 21st century has been exposed: the power that has propelled individuals thus far has been inverted from personal ego to global ego, and has locked us all into a vicious circle.

Warning signals are numerous and the time has come to acknowledge that "more of the same" is not enough. As Sunzi would phrase it: "when the paradigm is false, you are bound to fail in every battle”.

\subsection{When Science leads the way: a theoretical framework for modern crises}

The world is experiencing one of the worst financial crises in its entire history, therefore an analysis of what is happening can help understand how science can contribute to a better understanding of crisis and help in the stabilization of the global system.

\subsubsection{Science and finance: a good indication of what must (and must not) be done}

Benoit Mandelbrot, father of fractal theory, had understood a long time ago that the basic techniques 
P. Lagadec and B. Topper

of analysis developed in mathematics were very effective in some contexts but could be proven wrong when applied to complex phenomenon like price variation, which is calculated through the interaction of a large number of actors, using different strategies.

He had shown (Ref. 24) that the basic market assumption that price variations followed a simple Gaussian distribution (bell shaped), in which extreme changes ("black swans") were quasi inexistent, was deeply incorrect. As anyone who follows price movements knows all too well, statistically significant changes can be seen every day in the financial pages. And most of them are independent on the news (Ref. 25) i.e. they are large internal fluctuations, a phenomenon that any scientist knows to happen generically in a complex system, but that models based on Gaussian distributions assume to be non-existent. This proves that the Efficient Market Hypothesis and the BlackScholes model, commonly used by traders, are flawed. Over a year, the most important changes can occur in just a handful of days, and large price changes can happen without any external trigger.

One could instead use a Pareto distribution (Figure 2.) which has a long and thick "tail" and that can therefore account for black swan events. Of course, the math behind it is quite different, but the agreement with real data, and especially with extreme events, is much better (Ref. 25).

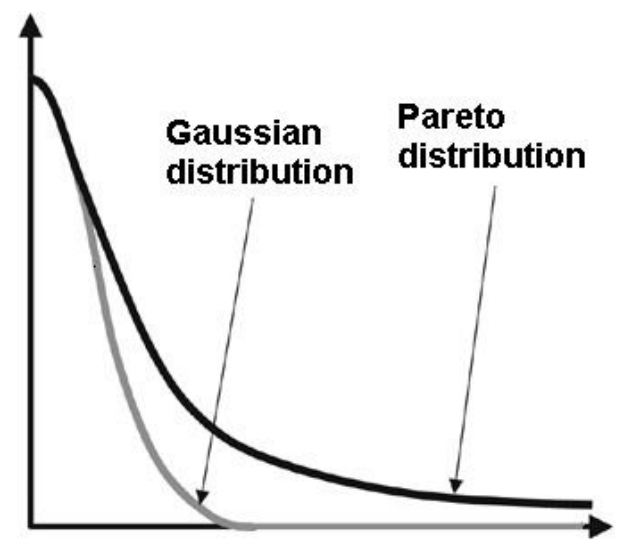

Figure 2. Schematic comparison of the tails of a Gaussian and a Pareto distribution

However, even though Mandelbrot's ideas were, and are still, considered groundbreaking and remarkable, they imply such a paradigm shift that they are largely ignored in the financial community that keeps working with "white swan only" models .

The context is the same on a more global scale. Our current scheme does not take into account complexity as being the inherent nature of the world we live in. Crises are still seen as an unusual event that can be treated separately, on its own, although they have become the defining process of our modern societies.

\subsubsection{The foundations of a new paradigm}

We do feel it important to recall that, when confronted with a large number of contradictory observations (Table 1), a paradigm shift, based on a more precise understanding of the dynamics of complex systems, can offer new insights and effective solutions to seemingly unpredictable behavior (Ref. 26).

In physics, the Lyapunov theorem on stability of systems states that "In the vicinity of its equilibrium points, the solutions of a non-linear system are similar to the ones of the equivalent linear system". This means that as long as your system is near its equilibrium point, you can use the techniques usually used for linear systems to get answers on the behavior of the nonlinear system. It is a non trivial theorem that can explain why techniques in risk and crisis management could still be used quite effectively during the previous decade or so, even though complexity had already become increasingly apparent.

However, the need, in the current framework of crisis management, for adding more and more parameters to describe the behavior of the system should have been a clear indication that something had changed. One cannot hope to describe a nonlinear dynamic system with a patchwork of simple parameters.

A non-linear system implies, in most cases, unpredictable behavior, such as the inversion of the Earth's magnetic field in physics. We must now prepare for the unexpected, and not predict the predictable. We must be more creative, learn to be surprised, and to act rationally and creatively during the phase of ignorance, information surge and shock. 


\section{(i) Be prepared to be surprised.}

Piling up written plans, rules, "coordination" committees and "communication" best practices remains the norm. People are prepared to manage according to solid rules, anchored on solid ground, and selected for their "inside the box" excellence. As soon as people discover that the situation does not correspond to the nominal framework, they tend to suffer instant paralysis and breakdown. "Nothing is more difficult and therefore more precious than the ability to decide," said Napoleon Bonaparte. While those words refer to battlefield commanders' ability to take action when under fire, they also resonate with anyone in charge who has ever had to handle a crisis situation.

In such a situation, the challenge is to make a decision quickly and accurately. In the current state of mind, a key component is to balance "gut feeling"--acting without thinking,--with "analysis paralysis"--thinking instead of acting. Acting impulsively can lead to a worsening of the situation. Likewise, overthinking a situation, weighing options endlessly can end up in leaving the entire operation in a state of stasis instead of recovering from the initial setback.

This is an invitation to radically change the vision of crisis and crisis handling, the education and training of all actors involved: "When training, Federal officials should not shy away from exercising worst-case scenarios that "break" our homeland security system” (Ref. 27). It is equally trying for people wrestling at the theoretical level, as Todd LaPorte stressed years ago: "What are our special intellectual obligations when we are burdened with the weight of theories of simple systems persisting in a world of vanishing simplicity?” (Ref. 28).

\section{(ii) Be prepared to be creative.}

The study of analogous physical systems can therefore teach us some new decisive visions and approaches. In the management of crises, it would mean:

- getting rid of automatisms when necessary and being ready not to act according to the plans
How Crises Model the Modern World

- taking a step back with the intervention of actors that are not submerged by the immediate operational constraints

- shaping a strategic reorientation with the realization that actors all have very different characteristic time-frames; the major challenge is less in terms of "doing" and more in terms of "knowing what to do, and who can help"

- considering innovation as a principle of action by constructing new convergences between the actors with regard to the principles, objectives and operating modes

- understanding crisis as an opportunity to change visions, resolutely opening new horizons for action.

This detour has taught us many lessons on how our views can be changed because of new, emerging properties stemming from the dynamic interactions in our society and how our techniques can be improved and rethought.

\section{Strategic recommendations: innovative methods put to the test}

"People in government are overwhelmed by crises [...]. They do not have much time to step back and consider the big picture" (Ref. 29). The same is true in the private sector. The practical challenge is to implement such a vision within the institutional design.

Modern crises must be seen as an opportunity for more innovation, for more action.

\subsection{Leadership}

As stated earlier, the major challenge today is to prepare leaders so that the creative approach will prevail at the right moment. Unfortunately, the entire organizational, administrative and institutional culture normally tends to fall into procedural thinking (Ref. 30).

And this fundamental logic is not going to be turned around by devoting a few hours a year to formal "crisis management" seminars - essentially oriented towards the teaching of the "good answers" and "best and certified talk-points". 
P. Lagadec and B. Topper

The leaders themselves should be mentally prepared to take an approach to intelligence and action that is more creative than procedural.

The problem is that our habits at times of emergency and crisis are usually just the opposite. With very little information available and even less of it verified, the leader must have the conviction and the vision to lead the community out of its initial disorientation, and to avoid the two pitfalls that are always present in extreme crises: bureaucratic inertia (where each organization waits until the crisis fits its codes and rules), and the general loss of nerve (not only within the public, but throughout the entire chain of command).

It is only by inspiring confidence that we can get through the ordeal, renew our energy, and come up with innovative plans and concrete paths to success. And confidence can be gained by the ability to call upon an experimented and ready-to-question crisis team. This innovative method is the "Rapid Reflection Force”, which was theorized a few years ago and has already been experimented in various cases.

But, as every new thinking process, the feedback will only be significant once a large scale implementation has been implemented.

\subsection{The Rapid Reflection Force: a discovery process}

The RRF is a group whose task is to help the leader to grasp and confront issues raised by unconventional situations. It does so by developing unconventional responses when usual toolkits and references turn out to be irrelevant, or indeed dangerous.

Along with the more "tactical" crisis teams, focused entirely on immediate operational responses, plans and logistics, such RRF teams promptly undertake four broad lines of interlinked questioning processes.

- What is the essence of the problem? It is crucial to understand the nature of the crisis, and to anticipate the possible mutations of the challenges.

- What are the major pitfalls? When the pressure of events becomes extreme, a very normal tendency is to become mired in the most counterproductive ruts. It is crucial, immediately, to think about the major errors to avoid. And the first is a wrong framing of the issue.

- What is the map of actors; what networks are needed? Extreme crises strike at the system in ways that are hard to anticipate, and involve complex emerging networks of actors. Mapping those networks is crucial.

- What constructive initiatives can the RRF suggest? The most important thing is not to pore over statistical lists or to compile all the information possible, but rather to try to discern one or a few critical initiatives that could introduce a new set of rules.

The ambition is not, or cannot be, to put the finger on 'the' magic formula, but to create conditions and avenues for improvement. The point is not only to be successful, but to act wisely.

A key success factor for such a support team, directly reporting to the highest level, is diversity of background and an ability to think and deliver creative options under pressure and in "the middle of nowhere”, with no information or worse, only deceptive information. The Rapid Reflection Force must also resist, through its constant questioning process, making the assumption that it has found the "right" course of action. RRF core responsibility is to open options to the highest level, not to substitute leadership.

In its essence, the RRF is a genuine "discovery" process applied to a sudden departure into Terra Incognita. It is a new managerial approach for an increasingly complex world. It clearly translates the shift required: a new vision to grasp the challenges, a genuine effort to escape from the mere application of conventional "best practices" - which is generally a terrible pitfall.

\subsection{Facing the real world}

This innovative approach to crisis management has already been implemented on a series of occasions, and is now gaining in maturity. Generic lessons have emerged from all of this. 
Électricité de France was the first to implement such a process within its crisis platform; the RRF was used in multiple circumstances (Refs. 31-32).

Real life incidents and exercises have shown that the RRF can genuinely become a pillar of strength around which an organization can group up:

- Over a seven-month period, (in August and November 2006, and then again in February 2007), one of EDF's nuclear plants (Chinon) was hit by a cluster of tragic events, as three of its employees committed suicide.

- In September 2007, a very ambitious simulation exercise was held by EDF, based on the scenario of a breakdown in information systems. The 'fog of war' was such that it was unclear whether the event was due to a national terrorist attack or merely to a localized disruption. This raised a serious challenge for the CE level, as the appropriate posture would differ dramatically depending on how the situation was interpreted. The RRF proved invaluable in helping the upper echelon make sense of the resulting 'phony war', and was the first to understand that the situation was not a case of global terror, but was due to insufficient protection at a single site - a conclusion which called for a specific communication strategy

- Communication policies have also changed radically. For years, the norm in crisis communication had been to prepare the initial communiqué, followed by a media briefing, and high-profile TV interviews, especially in nationally-televised newscasts. And again, the RRF was crucial numerous times as it helped the CE representative and the communication team to build a strategic response that reflected the new challenges.

The same kind of process has been used in 2006 by Aéroports de Paris. Efforts are being devoted just now to train people to use and implement such an RRF in various countries such as Belgium in the Railway system, or in Switzerland.

The RRF can benefit all. On a global scale, it can help an entire organization develop strength, coherence, stability, and strategic intelligence, and thereby address the most difficult - and increasingly
How Crises Model the Modern World

frequent - challenges of our turbulent times. The RRF is also a steady driver for benchmarking, partnerships, and shared initiatives at the Chancellery level.

Extensive feedback shows that these Rapid Reflection Forces are crucial for leaders, from blowing the whistle - when the challenge is not the frequently mentioned "weak signal", but the "strange" incomprehensible signal - to re-checking the organizational response, and above all to open entirely new pathways during difficult episodes. It's not only data harvesting, it's also data analysis.

On the one hand, it is now clear that the RRF can play a crucial role in the decision making process for leaders. But on the other hand it cannot, and should not, replace other functions: neither operations nor communication, nor above all, the organization's strategic team.

This initial feedback suggests where the goalposts are to be set: everyone within the crisis platform should be trained to take full advantage of the RRF, but they must also retain their own crucial mission.

But one cannot sufficiently stress that organizations and leaders only trained to consider known, independent, and common risks, only prepared to consider mapped crises, show strong reluctance to accepting any RRF process. They stick to preplanned courses of action, and they fail. The real challenge is a cultural change.

\subsection{Current Developments: The Center for Transatlantic Relations Advanced Seminars.}

In 2006, the Center for Transatlantic Relations (SAIS, Johns Hopkins University) launched the Project "Unconventional Crises, Unconventional Responses: Reforming Leadership in The Age of Catastrophic Crises and 'Hyper complexity'” (Ref. 33)

It sets up an international platform of leaders and experts that share questions, practices, and innovations. It brings together top officials from public sector (i.e. DHS, FEMA), critical networks (Energy, Banks, Transport, Information, etc.), NGOs and the Red Cross, and Academics worldwide with a challenging rule: the only 
P. Lagadec and B. Topper

questions explored are those that are not known, for which there are no ready-to-use solutions or plans.

A fresh impulse is now on its way with new and resolute signs of interest from the highest level of key organizations. The cornerstone is the understanding that crisis management is not so much a crucial need for additional "tool-boxes, practices, frameworks”, but rather "fresh vision" approaches and capacities to deal with hypercomplexity, systemic risks, and global volatility.

\section{Discussion}

This new frontier will confront us with totally unknown theatres of operations, with overlapping and rippling crises. Shaping the future will require new visions and practices if we want to rise to the challenge.

\subsection{New frontiers in a volatile world}

In our search for unconventional territories, we have chosen to pick four domains in which we think crisis reflects the interconnectivity and the complexity our societies have reached, and therefore the sectors that are among the most at risk. This short discussion should not be seen as a prediction game, but as an addendum to our analysis of the global situation and the major nodes of our societies, which are therefore critical components for its stability.

\subsubsection{Energy}

The most critical domain for coming crises is probably the energy sector, and specifically the disappearance of cheap and easily extractible oil reserves [34]. Without doubt this sector is most likely to trigger a global crisis that could jeopardize global economic growth and bring social upheavals in the coming decade. Cheap energy is a key source of economic growth, and not the other way round, because energy is the physical means of transforming the world.

The scarcity of this primary energy source, representing approximately $35 \%$ of the world energy production, is an event that humanity has never had to face, and that it is about to have to overcome.

\subsubsection{Cyber attacks}

World's public and private institutions are more and more subject to threat coming from the cyber world.

The information technology infrastructure is now vital for communication, commerce, and control of physical infrastructures, and is highly vulnerable to terrorist and criminal attacks. The sophistication of our world is in itself a source of vulnerability: information technology drives critical industries such as aviation, electricity or water supply, banking and finance.

Our time is one of global leaks, with the use of websites such as Wikileaks, and cyber attacks, when dispatched groups of individuals, like Anonymous and LulzSec decide to steal data or block a website. But also to cyber wars, as when Iran had to face a computer virus, Stuxnet, affecting its nuclear program.

The world institutions are effectively in a state of cyber-siege and cyber-chaos, enduring attacks from people who want to steal or reveal confidential information, to bring websites down, or to destroy as much information as possible.

\subsubsection{From unity to separation: towards geopolitical complexity}

Volatility and disconnection appear to transform institutional foundations on the international, national and regional levels.

This global shift - from cohesion to dysfunction, from unity to separation - is particularly clear in the emergence of separatist movements. For instance in Europe, the severe disagreements in Belgium between Flemish and Walloons. The country was without effective government for over a year. French-speaking Wallonia in the south and Flemishspeaking Flanders in the north disagree on pretty much everything, from the handling of the economy to the war in Libya.

This situation actually reflects a much broader problem.

The EU is getting more and more concerned that the divorce of Belgium could spark a domino effect across Europe: the Basque country leaving Spain, Scotland leaving the UK (the Scottish National 
Party won a majority of seats in Scotland's parliament during last election)... In Italy, the separatist attitudes are strong in the industrially advanced northern regions towards the poorer South of the country.

But separatist movements are also gaining momentum all over the World, in developed, emerging and developing countries alike.

Therefore we could witness a chain reaction of small states gaining independence. Such a plunge into the unknown would imply weaker governments threatened by inner rebellions, and a rise in tension between states with a surge in border disagreements. This would imply a completely new framework for crisis management, whatever the nature of the crisis.

\subsubsection{Debt issues and social upheavals}

After the 2007 financial crisis, most sovereign states had to help the banking system which constitutes the foundation of the global economy, and decided to implement stimulus packages to boost growth, which were all financed by a growing debt.

The debt issue is now a huge problem we are facing: investors are losing confidence in the ability of sovereign states to pay, and the subsequent budget cuts needed to restore confidence generates social upheavals.

First we heard about Greece. Then, we learnt about the "PIIGS" - a very inelegant acronym for Portugal, Ireland, Italy, Greece and Spain - who are having sovereign debt issues. These countries represent a growing percentage of the world GDP. Globalization means that the debt of each of these countries is owned by investors around the world.

For a long time, dissemination of risks meant greater safety, as risks were diluted among separate actors. Now that the world is global and interconnected, risk still seems to be distributed around the world, but because of global tight coupling nobody knows who is exposed, and to what level.

And now, at the time of writing, we are witnessing the emergence of a surprising global movement "Occupy Wall Street". It may be ephemeral. But it may be much more. Here again, nobody seems to be
How Crises Model the Modern World controlling or leading. Volatility could engender many different and surprising developments.

This last point is a perfect analogy for what global crisis has now become. But again, such explorations must not lead back to the common segmented approach to risks and crises. Crises today will most probably combine, in a strange and unanticipated way, many dimensions of such challenges and many others emerging brutally from nowhere. The imperative is not to categorize and apply, but to question the present and to shape the future.

\subsection{Research opportunities: what needs to be done}

It may be quite unusual for a paper on crisis management not to advocate for new tools or for new "best-practices". Our position it that crisis management has to reinvent its foundations if it is to become truly operational. This can only be done through a paradigm shift. Of course, this may seem far removed from the immediate realities, but when tactics has proven powerless as it is now the case, the first priority is to restore the strategic depth, global vision, revisiting and strengthening our theoretical grounds instead of rushing down the path of micro-management.

Calling for additional research efforts is a rule in any academic contribution. In most cases, authors are pleading for more research on specific subjects such as "children in disasters", "women in disasters", "emerging groups in crises”, etc.; or on specific dimensions - such as "communication in crises", "recovery after catastrophic disasters”, and so on

The new frontiers, the new global contexts that we are facing today call for a more radical shift in the research agenda. In Thomas Kuhn's words we need to go beyond "normal science" - which is fully appropriate as long as the usual paradigm works. As our basic assumptions - linearity, independence, etc. - have become ineffective, the time has come to translate that reality into science and research.

We need to fully accept the need for a paradigm shift, even if such a leap is always extremely tiring - "creative scientists must occasionally be able to live in a world out of joint” (Ref. 26). 
P. Lagadec and B. Topper

Some very specific questions have to be dealt with. In fact, every single question, reference, know-how, practice has to be questioned and re-formatted.

For instance, on matters of “crisis communication”, research has to address the new environment we live in: how to "communicate" when anyone can instantly reach billions of people.

But we certainly need something else. We have to prepare researchers in such a way that they can picture the world differently. As a starting point here, it would be useful to think of the decisive move made by eminent scientists in the USA at the turn of the $19^{\text {th }}$ Century in the field of public health: "Shortly before the Great War began, the men who wanted to transform American medicine succeeded. They created a system that could produce people capable of thinking in a new way, capable of challenging the natural order. They, together with the first generation of scientists they had trained formed a cadre who stood on alert, hoping against but expecting and preparing for the eruption of an epidemic. When it came, they placed their lives in the path of the disease and applied all their knowledge and powers to defeat it. As it overwhelmed them, they concentrated on constructing the body of knowledge necessary to eventually triumph.” (Ref. 35) We certainly have to address that kind of vital challenge today.

Obviously, a huge amount of work still needs to be done, especially in top education programs to train people to new global challenges. New answers must be searched for, and will surely be found, but we have to realize that "they will not simply fall as a gentle rain from the sky." (W. Shakespeare, The Merchant of Venice).

\section{References}

1. Yukiya Amano, International Atomic Energy Agency (IAEA) Director General, Vienna, 21 March 2011. http://www.unmultimedia.org/tv/unifeed/d/172 51.html

2. Barbara W. Tuchman, The March of Folly From Troy to Vietnam, Ballantine Books, New York, 1984.

3. Xavier Guilhou, "Devoir de protéger”: pourquoi le repenser?” La revue de géopolitique, 28 juillet 2011, Diploweb.com,
http://www.diploweb.com/Devoir-de-protegerpourquoi-le.html

4. U.S. House of Representatives: A Failure of Initiative, US House of Representative, Final Report of the Select Bipartisan Committee to Investigate the Preparation for and Response to Hurricane Katrina, US Government Printing Office, 15 February, 2006.

5. Steven Fink, Crisis management. Planning for the Inevitable. Amacom, American Management Association, 1986.

6. Robert Heath, Crisis Management for Managers and Executives, Financial times, Pitman, London, 1998.

7. Patrick Lagadec, Preventing Chaos in a Crisis Strategies for Prevention, Control and Damage Limitation, McGraw Hill, 1993.

8. Mark Haynes Daniell, World of Risk - Next Generation Strategy for a Volatile Era, John Wiley \& Sons, New York, 2000.

9. Uriel Rosenthal, Michael T. Charles, Paul 't Hart (Ed.): Coping with crises. The Management of Disasters, Riots and Terrorism, Charles C. Thomas Publisher, Springfield, Illinois, 1989.

10. Uriel Rosenthal, R. Arjen Boin, Louise K. Comfort (Ed.), Managing crises - Threat, Dilemmas, Opportunities, Charles C. Thomas Publisher, Springfield, Illinois, 2001.

11. Arjen Boin, "From Crisis to Disaster: Towards an Integrative Perspective”, in Ronald W. Perry \& E.L. Quarantelli, Editors: What is a Disaster? - New Answers to Old Questions, International Research Committee on Disasters, Xlibris Corporation, Lexington, KY, 2005, p. 153-172.

12. Patrick Lagadec, "Crisis Management in the Twenty-First Century - "Unthinkable” Events in "Unthinkable" Contexts", in Havidan Rodriguez, Enrico L. Quarantelli, and Russel Dynes: Handbook of Disaster Research, Springer, (Chapter 30, pp. 489-507), 2006.

13. Patrick Lagadec, "Over the Edge of the World", Crisis Response Journal, Volume 3, Issue 4, p. 48-49, 2007.

14. Karl E. Weick and Kathleen M. Sutcliffe, Managing the Unexpected, Resilient Performance in an Age of Uncertainty, John Wiley \& Sons, Inc.

15. Joshua Cooper Ramo, The Age of the Unthinkable - Why the New World Disorder constantly surprises us and What we Can Do 
About It, Little, Brown and Company, New York, 2009.

16. Gilles Sanson (Président de la Mission Interministérielle), " Evaluation des dispositifs de secours et d'intervention mis en œuvre à l'occasion des tempêtes des 26 et 28 décembre 1999 ", Rapport d'étape de la mission interministérielle, Premier Ministre, Juillet 2000.

17. The 9/11 Commission Report, Final Report of the National Commission on Terrorist Attacks Upon the United States, Authorized Edition, W.W. Norton \& Company, New York, 2004.

18. Admiral Thad Allen, "Hurricane Katrina: framing the issue - A weapon of mass destruction without criminal dimension", videotaped communication to Hans De Smet, Department of Economics, Management \& Leadership, Royal Military Academy, Brussels.

19. Senate Majority Leader on Economy http://abcnews.go.com/video/playerIndex?id=5 824988

20. Nassim Nicholas Taleb, The Black Swan - The Impact of the Highly Improbable, Allen Lane, Penguin Books, London, 2007.

21. Joseph A. Tainter, The collapse of complex societies, Cambridge University Press

22. RJ Zeckhauser and WK Viscusi, Risk within reason, Science 4 May 1990: 559-564. [DOI:10.1126/science.2333509].

23. Joint SEC/CFTC Report, Findings regarding the market events of May 6, 2010.

24. Benoit Mandelbrot, The variation of certain speculative prices. The Journal of Business of the University of Chicago, 36, 394-419. 1963.

25. Contributions of sciences and technologies to the evolution of financial markets, Public hearing of 14 October 2010, Mr Claude Birraux, deputy, president of OPECST

26. Tomas Kuhn, The Structure of Scientific Revolution, University of Chicago Press, 1962.

27. The White House: The Federal Response to Hurricane Katrina - Lessons Learned, 2006.

28. Todd. R. Ed. LaPorte, Organizational Social Complexity: Challenge to Politics and Policy, Princeton University Press, 1975.

29. Lee Hamilton, "Prologue”, in Thomas H. Kean and Lee H. Hamilton, Without Precedent, The Inside Story of the 9/11 Commission, Alfred A. Knoff, New York, 2006.

30. Young, James (2007), "Leadership in the age of unconventional crises and chaotic
How Crises Model the Modern World

environment”, personal video-taped communication.

31. Pierre Béroux, Xavier Guilhou, Patrick Lagadec, "Implementing Rapid Reflection Forces", Crisis Response Journal, vol. 3, issue 2, March 2007, pp. 36-37.

32. Pierre Béroux, Xavier Guilhou, Patrick Lagadec, "Rapid Reflection Forces put to the reality test", Crisis Response Journal, Vol 4, Issue 2, March 2008, pp. 38-40.

33. Erwan Lagadec, Leadership in Unconventional Crises, A Transatlantic and Cross-Sector Assessment, Center for Transatlantic Relations, The Paul Nitze School of Advanced International Studies, The Johns Hopkins University, Washington DC., 2009.

34. International Energy Agence, World Energy Outlook 2010

35. John M. Barry, The Great Influenza - The Epic Story of the Deadliest Plague in History, Penguin Books, New York, 2004,

\footnotetext{
i Senior Research Scientist at the Ecole Polytechnique (France); elected member of the French Academy of Engineering; Scientific advisor to various organizations confronted with unconventional risks and crises. Mail : plagadec@club-internet.fr

ii Theoretical physicist (UPMC /ENS Ulm), junior science and technology advisor. Mail : benjamin.topper@gmail.com
} 